\title{
Low-input, low-cost IPM program helps manage potato psyllid
}

by Sean M. Prager, Gregory Kund and John Trumble

Potato psyllid is a pest of solanaceous plants throughout much of the western United States, including California, where it has increased and is now overwintering. The psyllid affects its plant hosts from direct feeding and by transmitting a plant pathogenic bacterium, Lso. Millions of dollars of damages have occurred in the U.S. potato industry, and a large acreage of crops is susceptible in California. Control is complicated because different crops have different pest complexes and susceptibilities to Lso; currently most growers use multiple pesticide applications, including broad-spectrum insecticides. Results of our field trials at South Coast Research and Extension Center indicate that the use of broad-spectrum insecticides actually increases psyllid numbers in both peppers and potatoes. We have developed a low-input IPM program, which in field trials produced encouraging results in peppers, potatoes and tomatoes compared to broadspectrum insecticides. Economic analysis showed the low-input IPM approach was more cost effective than a standard insecticide program in tomatoes.

$\mathrm{T}$ he potato psyllid, Bactericera cockerelli Sulk (Hemiptera: Triozidae), also known as the tomato psyllid, is an insect pest on many important solanaceous vegetable crops grown in California. These include tomato (Solanum lycopersicum), bell pepper (Capsicum annum) and potato (Solanum tuberosum) (Butler and Trumble 2012a). Potato psyllid and its associated bacterial pathogen Lso have caused considerable damage to potatoes in other states, New Zealand, and Mexico. Now the psyllid is more than an occasional pest in California and is overwintering here. Susceptible crops in California are estimated in excess of 600,000 acres (250,000 hectares), including approximately 25,000 acres $(10,000$ hectares) of potatoes (USDA-NASS 2015).

Control is complicated because different crops have different pest complexes and susceptibilities to potato psyllid and Lso. Solanaceous weeds are alternate hosts. Sequential sampling plans are available for each of the main host crops, but are not widely used. Resistance to effective insecticides has been documented in Texas. Growers continue to use broad-spectrum insecticides. Our goal was to develop an IPM approach that would help growers avoid unnecessary insecticide applications, particularly of broad-spectrum insecticides, which our field studies show increase the incidence of the pest.

\section{Potato psyllid damage}

Potato psyllid has multiple mechanisms of causing damage. First, feeding by potato psyllid nymphs, and sometimes adults, can result in psyllid yellows, the symptoms of which include stunting and chlorosis of leaves, and in extreme cases plant death; psyllid yellows is believed to be the result of a currently unidentified toxin (Butler and Trumble 2012a). There are reports of psyllid yellows in potatoes and tomatoes but not in peppers.

Second, potato psyllids are the only known North American vector of a phloem-limited bacterial pathogen tentatively known as Candidatus Liberibacter

Online: http://dx.doi.org/10.3733/ca.v070n02p89
California has over 600,000 acres of crops that are susceptible to potato psyllid, including potato (shown here), tomato and bell pepper. The pest can be found throughout the year from San Diego to the Sacramento Valley.

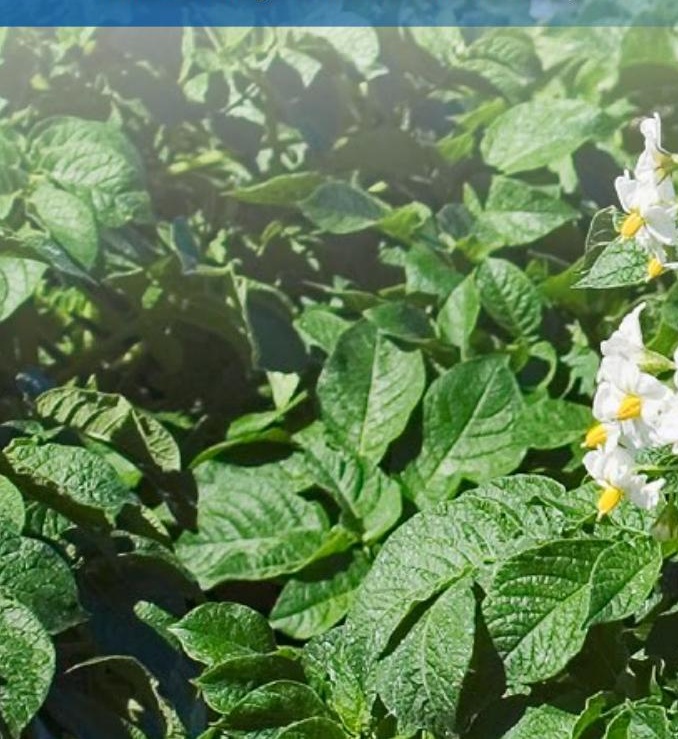



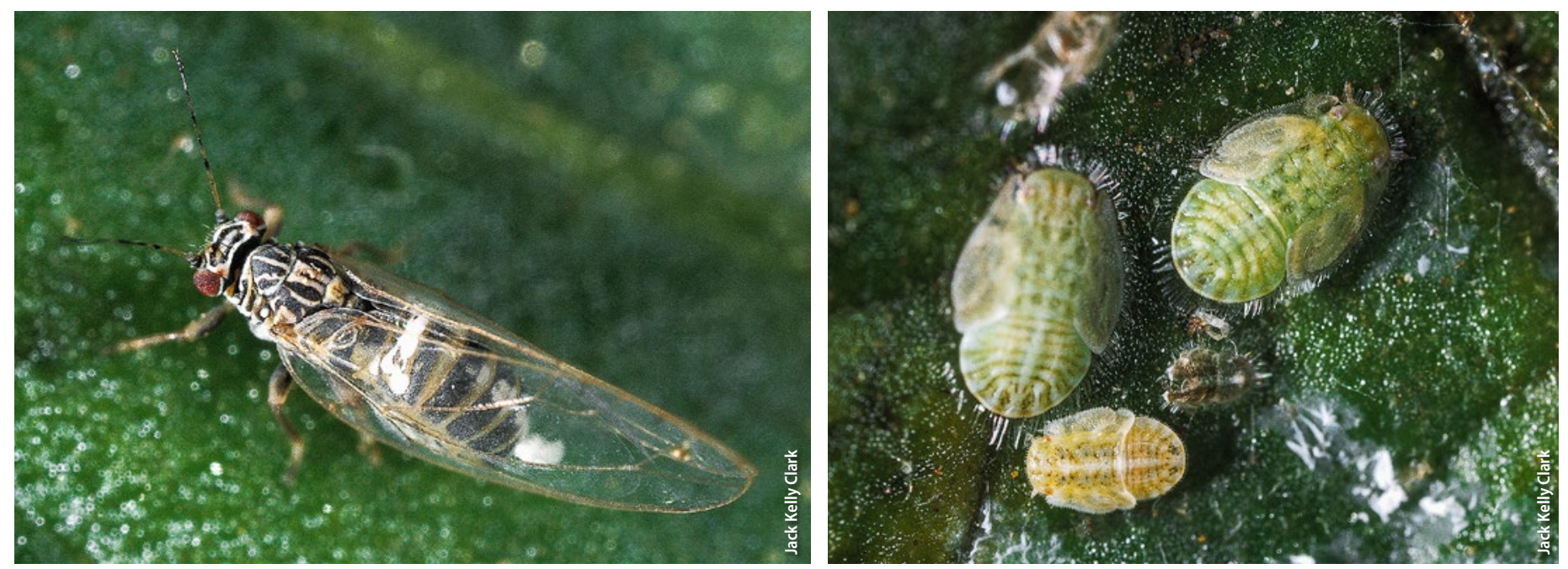

Psyllid adult, left, and psyllid nymphs, right. Adult potato psyllids are cicadalike in appearance. Although feeding by adults usually does not damage potato plants, their presence indicates a need to check for nymphs. Potato psyllid nymphs have a flattened, scalelike appearance.

currently there are no commercially available cultivars that exhibit resistance or tolerance to either the psyllid or Lso. Thus, control of potato psyllids is based on the application of insecticides (Guenthner et al. 2012).

In potatoes, where zebra chip disease is a particular threat, the set of insecticidal materials commonly used has been extensively tested and a list of recommended materials has been generated that includes systemic materials and those specific to sucking insects (Gharalari et al. 2009; Goolsby et al. 2007). In potatoes, the use of selective materials is practical, as the materials are effective against many of the common pest insects that threaten potatoes. Unfortunately, in bell pepper and tomatoes, these materials are not effective against many of the other insect pests that must be managed.

Grower resources such as the California UC IPM Pest Management Guidelines (ipm.ucanr.edu/PMG/crops-agriculture.html) incorporate best practices into their recommendations for pesticide use, but little information is available to growers that focuses on psyllid suppression while managing multiple other pests. Consequently, most of the current control strategies used by growers of bell peppers and tomatoes rely on broad-spectrum materials.

For example, in 2012 in bell peppers in California, the top insecticides applied (by weight) included the broad-spectrum materials permethrin (fifth most applied) and carbaryl (sixth most applied) (DPR 2013). Additionally, methomyl, a restricted use, highly toxic broad-spectrum material, was the 18th most applied pesticide when considered by area treated. Similarly, in 2012 in potatoes, the top 10 insecticides applied by weight included the broad-spectrum materials phorate, carbaryl, esfenvalerate and methomyl.

In potatoes, as mentioned above, new materials that are target-specific or systemic (and thus less harmful to beneficial insects) have been evaluated for control of potato psyllids. Among the small list of materials recommended or commonly used are two neonicotinoid materials (imidacloprid and thiamethoxam), two materials targeted at sucking insects (pymetrozine and spirotetramat) and the bacterial-derived abamectin (Guenthner et al. 2012). Some of these materials have been examined in greater detail than others. Imidacloprid and thiamethoxam have been tested for potential resistance development by the psyllid (Prager, Vindiola et al. 2013). These studies indicate that substantial resistance has developed to imidacloprid in southern Texas, and that the same population may also be developing resistance to thiamethoxam. Currently, there is no evidence of resistance in California.

Studies of the materials have led to more refined management recommendations. It has been determined that the method of application (drip versus soil drench) substantially affects the levels of active ingredient realized in the plant, with application through drip irrigation resulting in better control in potatoes and higher concentrations of the materials in plants (Prager, Vindiola et al. 2013). Foliar applications should be minimized or avoided as these are expensive and repeated use is believed to be one cause of the pesticide resistance development in Texas.

\section{Biological control}

There are no commercially available biological control agents available for potato psyllid. Biocontrol agents are available for purchase for some other pests, such as whiteflies and leafminers, that cause problems in potatoes, tomatoes and bell peppers, but in many cases these are not necessary if the native biological controls are not killed by pesticides (Trumble 1990).

For some insects like the beet armyworm, entire IPM programs have been developed based on the use of organically-approved microbial controls such as Bacillus thuriengiensis (Trumble et al. 1994), but pesticides still may be needed if other pests are present. When psyllids are present, conservation of existing natural enemies, such as spiders, lacewings and the parasitoid Tamarixia triozae, can provide additional control, though pesticides are the only currently available strategy to adequately reduce psyllids and suppress Lso. Therefore, it is critical to select pesticides that maximize the effects on the psyllids while minimizing the effects on beneficial arthropods.

\section{Low-input IPM program}

We have had success using a low-input IPM program based on pest monitoring 
and, as necessary, using pesticides (no organophosphates, carbamates or pyrethroids) that have few detrimental effects on beneficial insects, since beneficials have been shown to help reduce psyllid populations (Butler and Trumble 2012c). The low-input program uses an Insecticide Resistance Action Committee (IRAC) strategy for alternating the mode of action of pesticides to slow development of pesticide resistance. These concepts of resistance management and maximizing the effects of existing beneficial arthropods are incorporated in the program and do not require any specialized knowledge or action on the part of the grower adopting the program.

To use this program, pest control advisers (PCAs) first scout the fields, using a sequential sampling plan or similar approach, determine which pests are present, and then use a schematic (fig. 1) to choose the appropriate rotational strategy for the pest(s) present. When circles overlap, the rotation is expected to be effective against both pests. When a material appears in multiple circles, it can be expected to function for control against both (all) pests. When there is no overlap, pestspecific materials can be chosen for a single pest. This approach simplifies the selection of pesticides and minimizes the potential for unnecessary applications. Our research group has used the program successfully in field trials of several vegetable crops, including peppers, celery and tomato.

Tomato field trial. In multiple tomato field trials at the UC South Coast REC, we compared the low-input program with the standard chemical treatment of methomyl plus permethrin. There were four replicates per treatment, plots

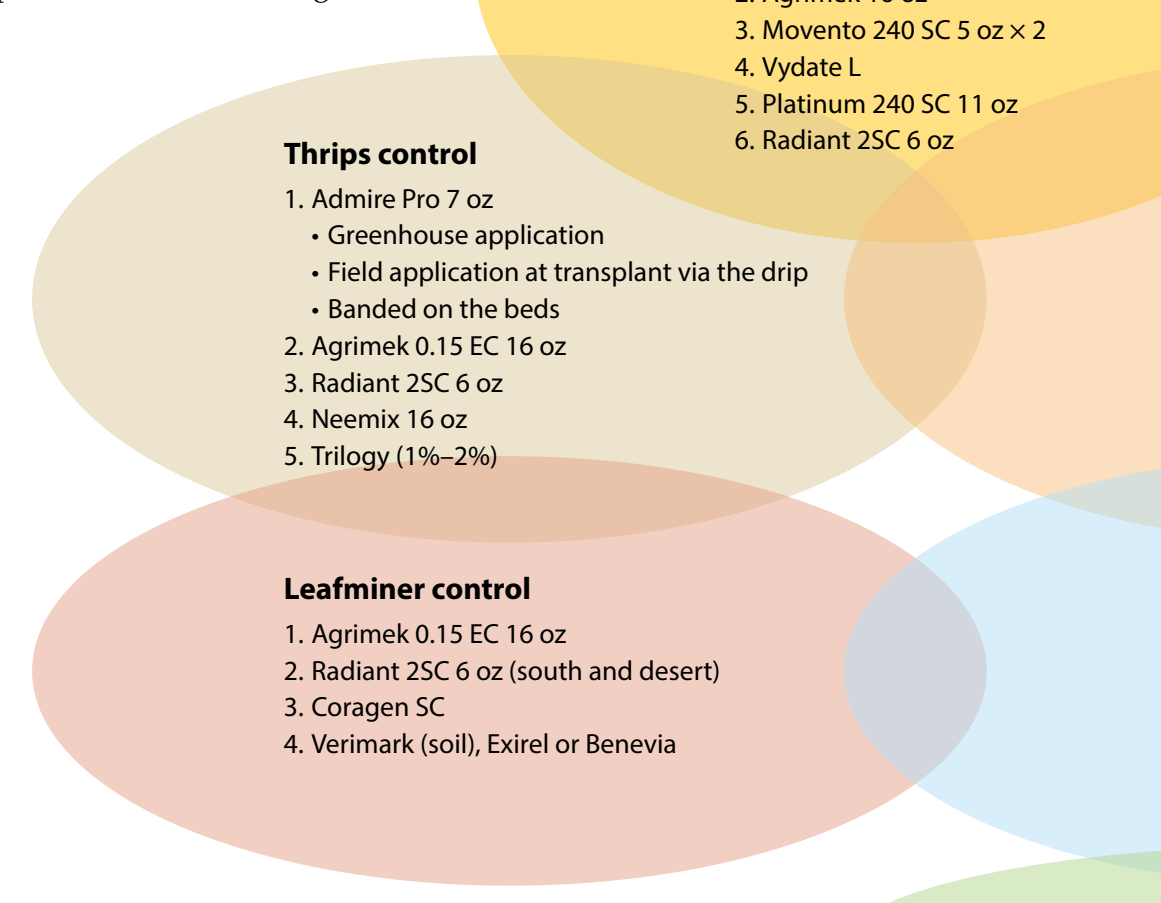

were four rows wide on 5-foot (1.58-meter) centers and 65 feet (20 meters) long and all applications were made with a commercial tractor-mounted boom sprayer. Yield measurements were taken at harvest from the two center rows of each plot. An economic analysis was made, including calculation of production costs and the dollar value of yields; see figure 2 .

The results were encouraging. Across the range of carton values, the net profit was greater for the low-input IPM program than for the standard chemical treatment. In our experience, growers readily adopt such programs when provided evidence of an economic benefit (Trumble 1998).

Potato and bell pepper field trials. In 2011 and 2014, we conducted trials on potatoes and bell peppers at South Coast REC, comparing plots treated with the broad-spectrum insecticides methomyl (Lannate, Dupont Crop Protection, Wilmington, Delaware) and permethrin (Pounce, FMC Corp.,

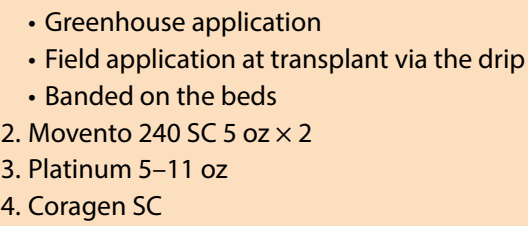

\section{Worm control}

1. Avaunt DG $3.5 \mathrm{oz}$

2. Synapse $24 \mathrm{WG} 3 \mathrm{oz}$

3. Xentari DF $1 \mathrm{lb}$

4. Radiant $2 \mathrm{SC} 6 \mathrm{oz}$

5. Intrepid 240F 8-16 oz

6. Coragen SC

7. Verimark (soil), Exirel or Benevia

Weevil control

1. Actara

- Provides some worm control

Fig. 1. A low-input IPM program for controlling potato psyllid in California bell peppers, tomatoes and potatoes includes selecting pesticides to match the pest population present and using materials with the least detrimental effects on beneficial insects. Each circle indicates an optimized IPM rotation for that particular pest. Numbers indicate order of application within the rotational strategy and do not imply efficacy (higher number $\neq$ greater efficacy). When circles overlap, the rotation is expected to be effective against both pests. When a material appears in multiple circles, it can be expected to function for control against both (all) pests. When there is no material in common between two circles, it may be necessary to make an additional application using a material from each of the pests' circles (rotation). Always check the insecticide label for specific crop use and rates. 
Philadelphia, Pennsylvania) to untreated control plots and to plots managed with the low-input IPM treatment described above as well as several chemicals commonly used in the control of psyllids in potatoes.

Potatoes ('Atlantic') and bell peppers ('Cal Wonder' in 2011, 'Baron' in 2014) were planted in identical-sized plots (4 rows wide, 5 -foot centers, 65 feet long), four replicates per treatment, using methods that approximate a commercial operation. Both bell peppers and potatoes were drip irrigated, and in 2014 potatoes were also sprinkler irrigated until approximately 1 week after emergence.

Insecticides were applied at labeled rates, using commercial application equipment, via a tractor-mounted boom, drip irrigation, or a soil drench as appropriate. Materials applied as either a drench or through chemigation were applied once at planting. All other sprays were made weekly, weather permitting. The combination methomyl and permethrin treatment was applied a minimum of six times.

Bell pepper and potato fields were sampled each year for the presence of potato psyllid. During sampling, five randomly selected whole plants per replicate (20 plants per treatment on every sample date) were inspected for the presence of eggs, nymphs and adults. In 2011 and 2014, mature-green to ripe bell pepper fruit were harvested from the center row of each replicate and examined for the presence of potato psyllid; in 2011, 200 fruit were examined from each replicate plot (800 per treatment); in 2014, 100 fruit were examined from each treatment plot (400 per treatment). Additional pests identified in the fields included Lepidoptera, aphids and lygus bugs.

These trials indicated that the use of broad-spectrum insecticides were associated with increased psyllid populations.

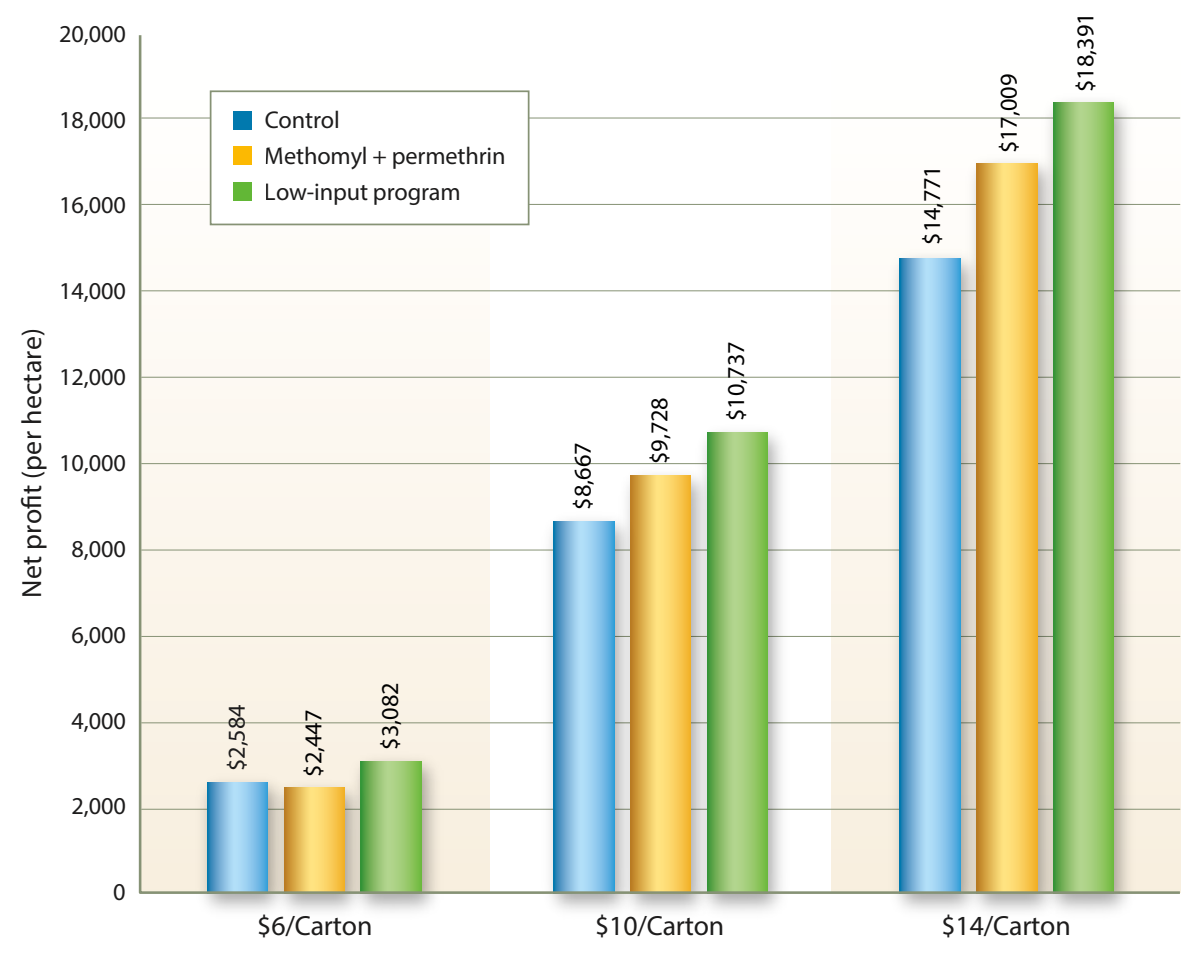

Fig. 2. Net profit per hectare in a tomato trial comparing a low-input IPM program and a standard chemical program (methomyl plus permethrin) for managing potato psyllid. Control plots (with no pesticide applications) were included to show whether the costs of pest management were warranted. The net profit was determined as the value of the marketable portion of the crop minus the horticultural costs (including the costs of pesticides and their application) needed to produce and harvest the crop. The dollar value of a 25-pound (11.3-kilogram) carton varies during the season and between years, but it generally ranges between $\$ 6.00$ and $\$ 14.00$.
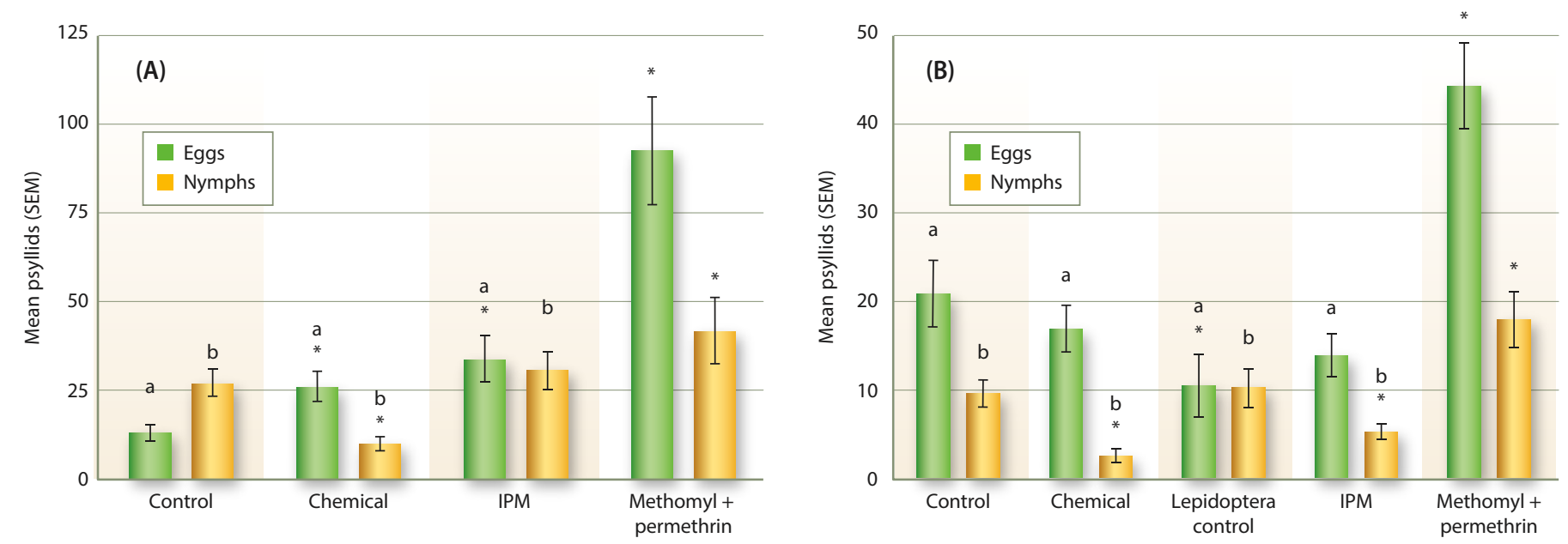

Fig. 3. The number of potato psyllid eggs and nymphs in field counts of bell peppers in (A) 2011 (GLM: $\left.X^{2}=22.8, d . f .=3,74, p<0.001\right)$ and (B) 2014 (GLM: $X^{2}$ $=33.0$, d.f. $=4,93, p<0.001$ ). Control = untreated with any insecticide; chemical = insecticidal materials used but without applying the IPM strategy; and Lepidoptera control $=$ the application of materials selected with a focus on controlling Lepidopteran pests. Letters indicate significant differences with the methomyl and permethrin treatment at $p<0.05$. Asterisks indicate significant difference with the control at $p<0.05$. 
with the methomyl and permethrin treatment in bell pepper fruit at harvest in 2014 (fig. 4).

In 2014 and 2015, bell pepper growers in the Central Valley reported outbreaks of potato psyllids with large numbers of nymphs, adults and honeydew on plants and especially fruit. The growers were targeting numerous pests, including pepper weevil and potato psyllid, and applying many materials, including some broad-spectrum insecticides. It had been previously suggested, before our trials, that some broad-spectrum insecticidal

\section{In our potato plots... treatments of methomyl and permethrin resulted in a statistically significant increase in the number of psyllid nymphs compared to the other treatments.}

materials may lead to increased potato psyllid populations; the study was done in greenhouses in Colorado (Al-Jabr and Cranshaw 2007), but the effect was not tested in the field.

In our potato plots at South Coast REC in 2014, as in peppers, treatments of methomyl and permethrin resulted in

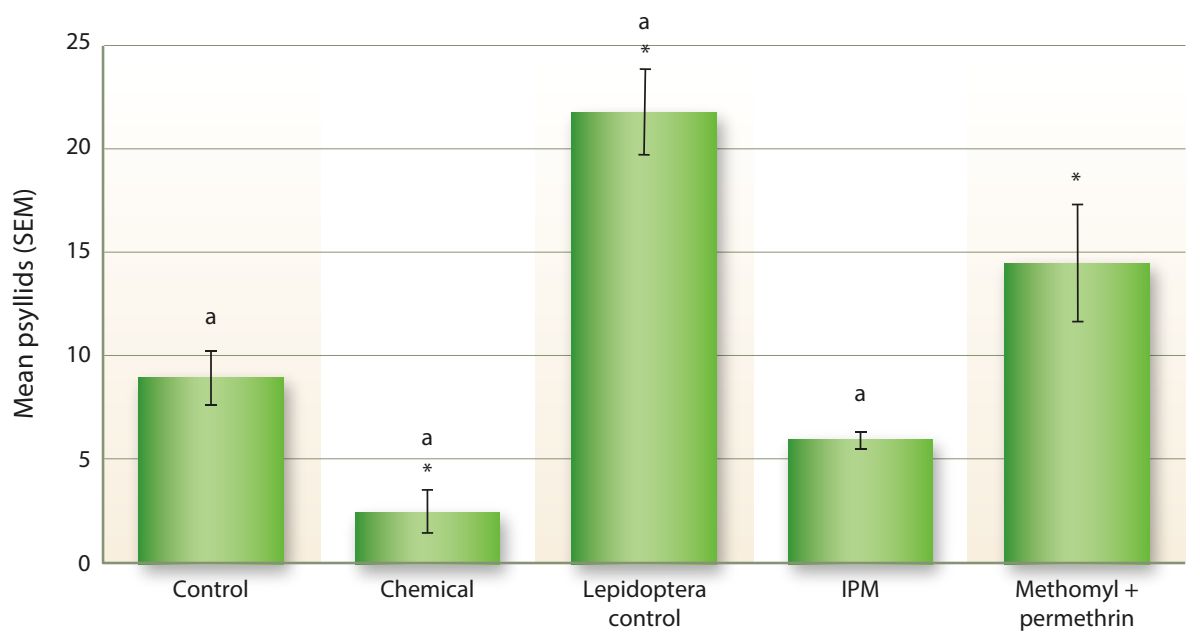

Fig. 4. The number of potato psyllid nymphs in bell pepper fruit at harvest in 2014. There is an overall significant trend (GLM: $X^{2}=87.4$, d.f. $=5,29, p<0.001$ ). The insects rarely, if ever, oviposit on the fruit, so there are no data on egg numbers. Control = untreated with any insecticide; chemical = insecticidal materials used but without applying the IPM strategy; Lepidoptera control = the application of materials selected with a focus on controlling Lepidopteran pests. Letters indicate significant differences with the methomyl and permethrin treatment at $p<0.05$. Asterisks indicate significant difference with the control at $p<0.05$.

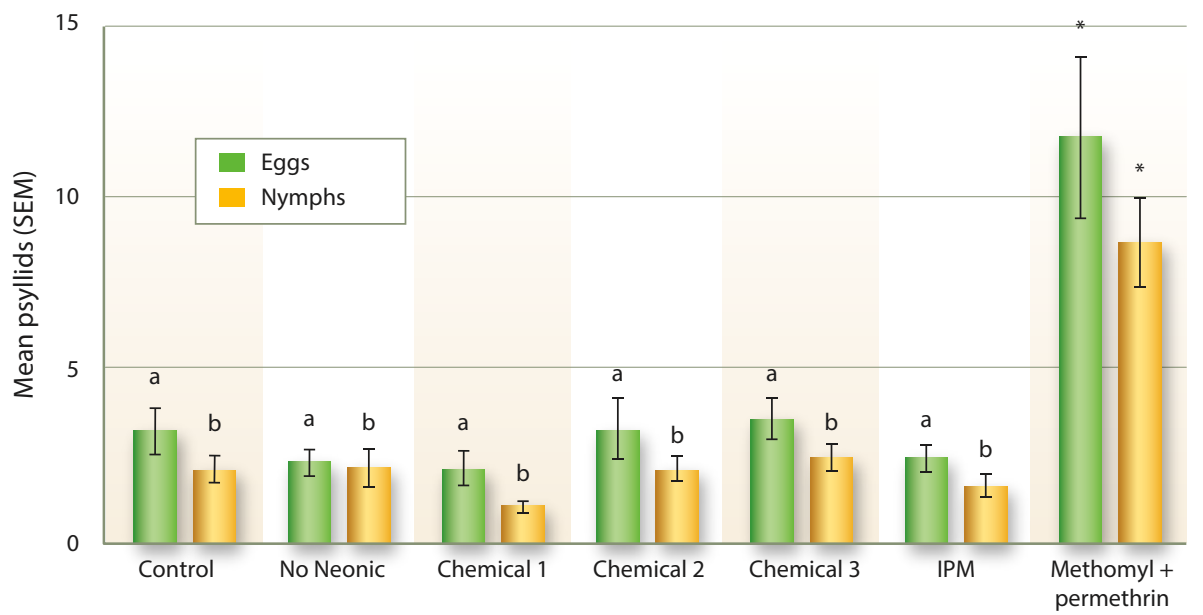

Fig. 5. The number of potato psyllid eggs and nymphs in field counts of potatoes in 2014. Chemicals 1,2 and 3 are commonly used in the control of psyllids in potatoes, including some neonicotinoid materials, while "No neonic" includes similar common materials but no neonicotinoid insecticides. Letters indicate significant differences with the methomyl and permethrin treatment at $p<0.05$. Asterisks indicate significant difference with the control at $p<0.05$. a statistically significant increase in the number of psyllid nymphs compared to the other treatments (GLM: $X^{2}=64.8$, d.f. $=11,226, p<0.001$; fig. 5). This pattern was also observed with respect to the number of eggs (GLM: $X^{2}=49.8$, d.f. $=11$, 226, $p<0.001$; fig. 5), with significantly more eggs counted in the methomyl and permethrin treatment than in the other treatments. Greater numbers of nymphs and eggs are likely to have been associated with greater numbers of adults as well, although this was not examined because adults are quite difficult to count in the field.

\section{Management challenges}

Management of potato psyllid in California is likely to become increasingly difficult due to a combination of factors: limits and regulations on pesticide applications, the apparently increasing range of the pest (in 2011 it was found overwintering in Washington state and Idaho), its recently acquired habit of overwintering in California rather than migrating, and the relative abundance of host crops. Additionally, since the psyllid is not the sole pest on many of its host crops, it must be managed in conjunction with other pests.

Feeding damage, and the "mechanical damage" of sooty molds, can be managed with limited insecticide applications and moderate economic thresholds. This is because the damage is associated with relatively high densities of psyllids; this is the case in both tomatoes and bell peppers. In potatoes, since zebra chip is a concern, a more conservative approach may be necessary. Our studies indicate that in peppers and tomatoes, a low-input IPM strategy can be adopted that is economically viable and effective against the complex of potential pests. The approach may also be suitable to potatoes when Lso is not a consideration, but is unlikely to be effective or adopted in areas (or cultivars) in which Lso is a particular risk.

Lso-susceptible crops present a different challenge. Lso can be rapidly transmitted by even a single psyllid given an exposure of just a few hours (Butler et 
al. 2012). The resulting infected plants currently cannot be cured of the infection. These severe consequences dictate a near zero-tolerance approach in crops such as potatoes grown for chipping or French fries - meaning that the lowinput IPM approach we present here may not be practical. Further, the nature of Lso influences the insecticidal materials that a grower can use. For example, some systemic insecticides have proven effective against potato psyllid, yet they must be ingested by the insect - but feeding increases the risk of pathogen transmission. Some insecticidal compounds, such as imidacloprid, have been shown to have anti-feedant properties in addition to toxicity (Butler et al. 2012). Other anti-feedant materials, such as pymetrozine (Fulfill,
Syngenta AG, Basel, Switzerland), may result in low insect mortality: We examined pymetrozine on tomato and potato plants in controlled greenhouse experiments, with the maximum allowable label rates, and found that following both 24-hour and 48-hour exposures, adult psyllids survived as well as those exposed to untreated control plants sprayed with water. However, it has yet to be determined if psyllids can transmit Lso following exposure to pymetrozine; it is possible that exposure to pymetrozine results in increased psyllid populations but not in the spread of Lso. In such a scenario, the efficacy would differ among crops based on the perceived threat from Lso.

Finally, it is increasingly important that management of the potato psyllid take an area-wide approach that considers all potential host crops. Psyllid movement between crops, timing of crop planting, and which crops are adjacent to others all need to be considered. There is much research that still needs to be done to address potato psyllid control. CA

S.M. Prager is Assistant Specialist, G. Kund is Staff Research Associate and J. Trumble is Distinguished Professor in the Department of Entomology at UC Riverside.

This research was funded by the California Pepper Commission, California Potato Research Advisory Board and a USDA-SCRI grant. We would like to thank Dave Wetovic and the South Coast Research and Extension Center for their continuous support of our field trials.

\section{References}

Al-Jabr AM, Cranshaw WS. 2007. Trapping tomato psyllid, Bactericera cockerelli (Sulc) (Hemiptera: Psyllidae), in greenhouses. Southwest Entomol 32:25-30.

Butler CD, Trumble JT. 2012a. The potato psyllid, Bactericera cockerelli (Sulc) (Hemiptera: Triozidae): Life history, relationship to plant diseases, and management strategies. Terr Arthro Rev 5:87-111.

Butler CD, Trumble JT. 2012b. Spatial dispersion and binomial sequential sampling for the potato psyllid (Hemiptera: Triozidae) on potato. Pest Manag Sci 142:247-57.

Butler CD, Trumble JT. 2012c. Identification and impact of natural enemies of Bactericera cockerelli in Southern California. J Econ Entomol 105:1509-19.

Butler CD, Walker GP, Trumble JT. 2012. Feeding disruption of potato psyllid, Bactericera cockerelli, by imidacloprid as measured by electrical penetration graphs. Entomol Exp Appl 142:247-57.

Compere H. 1915. Paratrioza cockerelli (Sulc). Monthly Bulletin California State Commission Horticulture 4:574. Crosslin JM, Munyaneza JE, Brown JK, Liefting LW. 2010. A history in the making: Potato zebra chip disease associated with a new psyllid-borne bacterium —a tale of striped potatoes. APSnet Features. doi:10.1094/APSnetFeature-2010-0110.

Diaz-Montano J, Vindiola BG, Drew N, et al. 2013. Resistance of selected potato genotypes to the potato psyllid (Hemiptera: Triozidae). Am J Potato Res 91:363-7. doi:10.1007/s12230-013-9356-6.

[DPR] California Department of Pesticide Regulation. 2013. California Pesticide Information Portal. http://calpip.cdpr.ca.gov/main.cfm (accessed 2015).
Gharalari AH, Nansen C, Lawson DS, et al. 2009. Knockdown mortality, repellency, and residual effects of insecticides for control of adult Bactericera cockerelli (Hemiptera: Psyllidae). J Econ Entomol 102:1032-8.

Goolsby JA, Adamczyk J, Bextine B, et al. 2007. Development of an IPM program for management of the potato psyllid to reduce incidence of zebra chip disorder in potatoes. Subtrop Plant Sci 59:85-94.

Greenway G. 2014. Economic impact of zebra chip control costs on grower returns in seven US states. Am J Potato Res 91:714-9.

Guenthner J, Goolsby J, Greenway G. 2012. Use and cost of insecticides to control potato psyllids and zebra chip on potatoes. Southwest Entomol 37:263-70.

Hansen A, Trumble JT, Stouthamer R, Paine TD. 2008. A new huanglongbing species, Candidatus Liberibacter psyllaurous, found to infect tomato and potato, is vectored by the psyllid Bactericera cockerelli (Sulc). Appl Environ Microb 74:5862-5.

Liu D, Trumble JT. 2004. Tomato psyllid behavioral responses to tomato plant lines and interactions of plant lines with insecticides. J Econ Entomol 97:1078-85.

Prager SM, Butler CD, Trumble JT. 2013. A sequential binomial sampling plan for potato psyllid (Hemiptera: Triozidae) on bell pepper (Capsicum annum). Pest Manag Sci 69:1131-5.

Prager SM, Butler CD, Trumble JT. 2014. A binomial sequential sampling plan for Bactericera cockerelli (Hemiptera: Triozidae) in Solanum lycopersicum (Solanales: Solanacea). J Econ Entomol 107: 838-45.
Prager SM, Esquivel I, Trumble JT. 2014. Factors influencing host plant choice and larval performance in Bactericera cockerelli. PLOS ONE 9(4):e94047.

Prager SM, Vindiola B, Kund GS, et al. 2013. Considerations for the use of neonicotinoid pesticides in management of Bactericera cockerelli (Šulk) (Hemiptera: Triozidae). Crop Prot 54:84-91.

Rojas P, Rodríguez-Leyva E, Refugio Lomeli-Flores J, Liu T-X. 2014. Biology and life history of Tamarixia triozae, a parasitoid of the potato psyllid Bactericera cockerelli. BioControl 60:27-35.

Trumble JT. 1990. Vegetable insect control with minimal use of insecticides. HortScience 25:159-64.

Trumble JT. 1998. IPM: Overcoming conflicts in adoption. Integrated Pest Manag Rev 3:195-207.

Trumble JT, Carson WG, White KK. 1994. Economic analysis of a Bacillus thuringiensis-based IPM program in fresh market tomatoes. J Econ Entomol 87:1463-9.

[USDA-NASS] USDA National Agricultural Statistics Service. 2015. Data and statistics. www.nass.usda.gov/ Data_and_Statistics/Citation_Request/index.php (accessed 2015).

Wuriyanghan H, Rosa C, Falk BW. 2011. Oral delivery of double-stranded RNAs and siRNAs induces RNAi effects in the potato/tomato psyllid, Bactericera cockerelli. PLOS ONE 6(11):e27736.

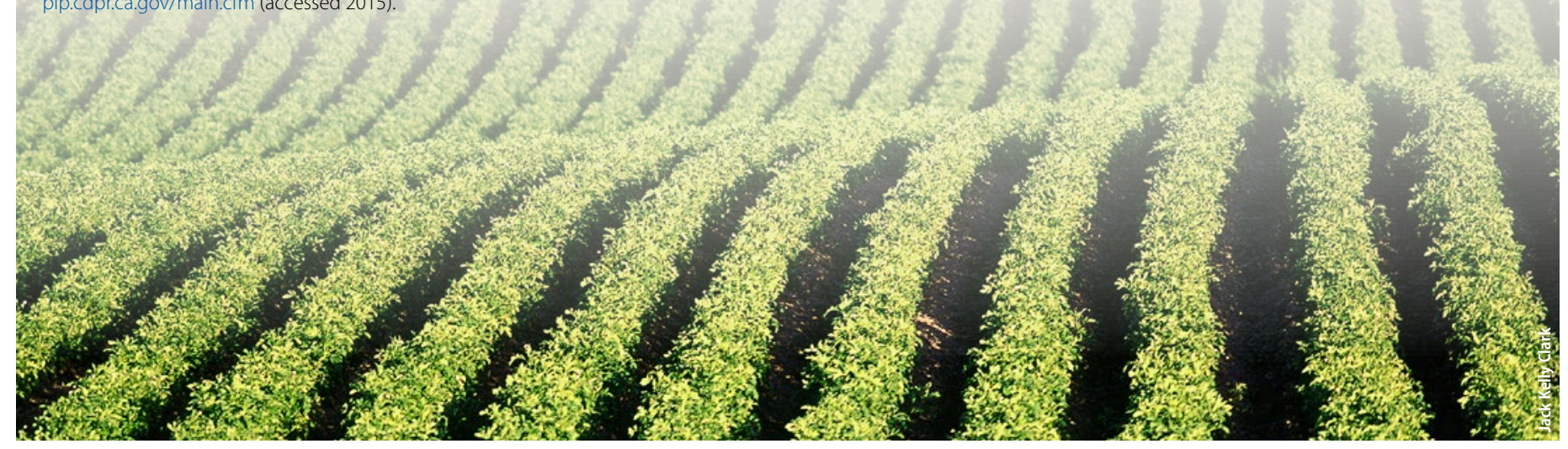

